\title{
Knowledge and practice of periodic abstinence among women in India
}

\author{
Begum Shahina ${ }^{1,2^{*}}$, Dwivedi Sada Nand ${ }^{1}$, Mittal Suneeta ${ }^{1}$, Pandey Arvind $^{3}$ \\ ${ }^{1}$ All India Institute of Medical Sciences, New Delhi, India \\ ${ }^{2}$ National Institute for Research in Reproductive Health, Mumbai, India; \\ *Corresponding Author: shahina_appe@yahoo.com \\ ${ }^{3}$ National Institute of Medical Statistics, New Delhi, India
}

Received 3 April 2013; revised 10 May 2013; accepted 20 May 2013

Copyright (C) 2013 Begum Shahina et al. This is an open access article distributed under the Creative Commons Attribution License, which permits unrestricted use, distribution, and reproduction in any medium, provided the original work is properly cited.

\begin{abstract}
The use of contraceptive method to avoid pregnancy is a multifaceted phenomenon. Worldwide, 20 percent of married women of reproductive age are currently using periodic abstinence. To assess the knowledge and practice of periodic abstinence among currently married pregnant women, data were collected from the pregnant women attending the Department of Obstetrics and Gynaecology, All India Institute of Medical Sciences, New Delhi, India. One thousand three hundred and thirty one (1331) currently married pregnant women were interviewed face-to-face. Approximately $\mathbf{2 9 . 3}$ percent of women were aware of the abstinence method, $\mathbf{1 1 . 5}$ percent women had history of using it. In-depth finding shows that 84.9 percent women did not have correct knowledge of fertile window of a menstrual cycle. Counseling about the correct fertile window of a menstrual cycle may increase the effectiveness of methods and hence reduce the incidence of unwanted pregnancies.
\end{abstract}

Keywords: Contraceptive; Natural Method; Rhythm; Safe Period Method; Traditional Method

\section{INTRODUCTION}

The choice of modern or traditional contraceptive method is a multifaceted phenomenon. Worldwide, 20 percent of married women of reproductive age are currently using a periodic abstinence [1]. In India, 5 percent of currently married women are relying on periodic abstinence [2]. Periodic abstinence is a method where couples can avoid having sexual intercourse on certain days of the month when the woman is more likely to become pregnant. Women are potentially fertile only 6 to 8 days of a menstrual cycle but how to identify these days is very important [3]. The traditional and easy formula is to keep track of length of menstrual period for at least six cycles and then subtract 11 days from the longest cycle and 18 days from shortest one to get the fertile window of a menstrual cycle [4]. The methods indicate that the fertile window may vary among women according to theirs' menstrual cycles [5]. To overcome this problem some researchers proposed the fixed duration of fertile window, i.e. from $9^{\text {th }}$ to $19^{\text {th }}$ days [4], $8^{\text {th }}$ to $19^{\text {th }}$ days [6], and $10^{\text {th }}$ to $17^{\text {th }}$ days [7] of a menstrual cycle. Among these proposed fertile window, method from $9^{\text {th }}$ to $19^{\text {th }}$ days is considered as standard days method [4] and it is 95 percent effective when used correctly [8]. There was lack of correct knowledge of fertile window period of a menstrual cycle among women [6,9]. The percent of users with correct knowledge of the fertile period varies from $8 \%$ to $91 \%$ [10]. In India, there has been little research into women's knowledge and understanding of the fertile period of a menstrual cycle. The present paper presents the knowledge of fertile window of a menstrual cycle among women who had heard of periodic abstinence and its use.

\section{METHODS}

Data were collected from 1331 currently married pregnant women attending the clinics of Obstetrics and Gynaecology at the All India Institute of Medical Sciences (AIIMS), New Delhi. Women who consented to participate in a study on unwanted pregnancieswere interviewed face-to-face using a structured questionnaire which includes demographic, socio economic characteristics and birth history. Women were asked whether they had heard of periodic abstinence and if yes, the knowledge of fertile window of a menstrual cycle. The responses were 
recorded as verbatim and further categorized as having correct knowledge of fertile window considering from $9^{\text {th }}$ to $19^{\text {th }}$ days, i.e. standard method [4] and also duration containing this interval.

\section{RESULTS}

\subsection{Awareness of Periodic Abstinence}

Out of 1331 currently married pregnant women, 390 (29\%) had heard of the periodic abstinence. Significantly higher percentage (32.6\%) of women aged 25 or more years were aware of the periodic abstinence method than that of women aged less than 25 years (21.6\%). As the year of schooling increased the knowledge of the safe period method also significantly increased. Significantly more $(43.9 \%)$ of working-women had heard of safe period method than non-working women (25.9\%). Awareness of periodic abstinence method significantly decreased with increased in parity. Significantly higher proportions of ever users of modern family planning methods heard of periodic abstinence than their counter- parts.

\subsection{Correct Knowledge of Fertile Window of a Menstrual Cycle}

Table 1 presents accuracy of the knowledge of fertile window of a menstrual cycle. It is evident that most of the women (96.6 percent) acquired inaccurate knowledge of fertile window. Higher proportion of women aged 25 years or more, schooling more than 12 years, working, with no living children and ever users of any modern family planning methods had correct knowledge of fertile window than their counterparts.

\subsection{Ever User of Periodic Abstinence Method}

It was found that 11.5 percent had ever used periodic abstinence (Table 1). The history of use of periodic abstinence was common in women aged 25 years or more (13.2\%), years of schooling more than $12(19.4 \%)$, working (17.8\%), belong to nuclear family (13.5\%) and

Table 1. Percent distribution of women by awareness, correct knowledge and practice of periodic abstinence according to selected background characteristics.

\begin{tabular}{|c|c|c|c|}
\hline Background characteristics & $\begin{array}{c}\text { Awareness of method } \\
\text { N [\% (95\% CI)] }\end{array}$ & $\begin{array}{c}\text { Correct knowledge of method } \\
\text { N [\% (95\% CI)] }\end{array}$ & $\begin{array}{c}\text { Ever used method } \\
\mathrm{N}[\%(95 \% \mathrm{CI})] \\
\end{array}$ \\
\hline \multicolumn{4}{|l|}{ Current age (years) } \\
\hline$<25$ & $87[21.6(17.6,25.7)]$ & $10[2.5(1.0,4.0)]$ & $30[7.5(4.9,10.0)]$ \\
\hline$\geq 25$ & $303[32.6(29.6,35.6)]$ & $50[5.4(3.9,6.8)]$ & $123[13.2(11.1,15.4)]$ \\
\hline \multicolumn{4}{|l|}{ Years of schooling } \\
\hline $0-4$ & $36[13.5(9.4,17.6)]$ & $4[1.5(0.0,3.0)]$ & $21[7.9(4.6,11.1)]$ \\
\hline $5-9$ & $57[20.1(15.5,24.8)]$ & $6[2.1(0.4,3.8)]$ & $24[8.5(5.2,11.7)]$ \\
\hline $10-12$ & $118[26.7(23.4,31.9)]$ & $10[2.4(0.9,3.8)]$ & $38[9.0(6.2,11.6)]$ \\
\hline more than 12 & $176[51.2(45.4,55.8)]$ & $40[11.1(8.0,14.6)]$ & 70 [19.4 (15.6, 23.9)] \\
\hline \multicolumn{4}{|l|}{ Religion } \\
\hline Hindu & $355[29.4(26.8,31.9)]$ & $54[4.5(3.3,5.6)]$ & $143[11.8(10.0,13.6)]$ \\
\hline Non-Hindu & $35[28.7(20.7,36.7)]$ & $6[4.9(1.1,8.8)]$ & $10[8.2(3.3,13.1)]$ \\
\hline \multicolumn{4}{|l|}{ Working } \\
\hline Yes & $111[43.9(37.8,50.0)]$ & $24[9.5(5.9,13.1)]$ & $45[17.8(13.1,22.5)]$ \\
\hline No & $279[25.9(23.3,28.5)]$ & $36[3.3(2.3,4.4)]$ & $108[10.0(8.2,11.8)]$ \\
\hline \multicolumn{4}{|l|}{ Parity } \\
\hline 0 & $106[37.6(31.9,43.2)]$ & $22[7.8(4.7,10.9)]$ & $23[8.2(5.0,11.4)]$ \\
\hline 1 & $133[30.6(26.3,35.0)]$ & $17[3.9(2.1,5.7)]$ & $55[12.7(9.5,15.8)]$ \\
\hline $2+$ & $151[24.6(21.2,28.0)]$ & $21[3.4(2.0,4.8)]$ & $75[12.2(9.6,14.8)]$ \\
\hline \multicolumn{4}{|l|}{ Type of family } \\
\hline Nuclear & $194[29.2(25.7,32.6)]$ & $32[4.8(3.2,6.4)]$ & $90[13.5(10.9,16.1)]$ \\
\hline Extended & $196[29.4(26.0,32.9)]$ & $28[4.2(2.7,5.7)]$ & $63[9.5(7.2,11.7)]$ \\
\hline \multicolumn{4}{|c|}{ Ever use modern contraceptive method } \\
\hline Yes & $235[33.6(25.6,31.8)]$ & $42[5.1(3.6,6.6)]$ & $118[14.4(12.0,16.8)]$ \\
\hline No & $115[22.4(18.8,26.1)]$ & $18[3.5(1.9,5.1)]$ & $35[6.8(4.6,9.0)]$ \\
\hline Total & $390[29.3(26.9,31.7)]$ & $60[4.5(3.4,5.6)]$ & $153[11.5(9.8,13.2)]$ \\
\hline
\end{tabular}


ever user of any modern contraceptive methods (14.4\%).

\subsection{Knowledge of Fertile Window of a Menstrual Cycle}

Table 2 shows that the knowledge of fertile window of a menstrual cycle varies among women who had heard of periodic abstinence. Higher percentage (31.5\%) of women stated that first 10 - 15 days of a menstrual cycle are fertile period. Some of them considered first 19 to 21 days, from $7^{\text {th }}$ to $20^{\text {th }}$ days $(0.3 \%)$, and from $8^{\text {th }}$ to $23^{\text {rd }}$ days $(0.5 \%)$ as fertile window of a menstrual cycle, and some of them considered 5 to 7 days before menstruation (0.8\%), 5 - 8 days before \& after menstruation (6.4\%) and first 8 days after menstruation (3.6\%) as non-fertile period of menstrual cycle. Approximately, 5.9\% of women had heard of the method but did not know the fertile window of a menstrual cycle. Only 60 women would not be at risk of unwanted pregnancy if they use it whereas 84.6 percent women would be at risk of unwanted pregnancy if they use this method because of incorrect knowledge.

\section{DISCUSSION}

The present study showed that 29.3 percent of women had heard of periodic abstinence method. Majority of them were having inaccurate knowledge of fertile period of a menstrual cycle and 11.5 percent women had practiced it. The knowledge of fertile window of a menstrual cycle varies among women. Most of the women stated mid cycle of a menstrual cycle was a fertile window, while stating the day 14.4 percent women stated it wrongly, i.e. $10^{\text {th }}-18^{\text {th }}$ days, $10^{\text {th }}-25^{\text {th }}$ days, and $12^{\text {th }}-$ $26^{\text {th }}$ days.

Though some of the women had not accurate knowledge of fertile period but they would not be at risk of pregnancy because they abstain from sex for longer period like considering first 19 to 21 days of a menstrual cycle as fertile period, from $7^{\text {th }}$ to $20^{\text {th }}$ days, from $8^{\text {th }}$ to $23^{\text {rd }}$ days as fertile window of a menstrual cycle, while5 to 7 days before menstruation, and first 8 days after men-

Table 2. Knowledge of fertile window (verbatim) among women who had heard of periodic abstinence method and are risk of pregnancy if they practice it.

\begin{tabular}{|c|c|c|}
\hline Verbatim & Percent $(\mathrm{N}=390)$ & At risk of pregnancy \\
\hline 5 to 7 days before menstruation are non-fertile period & $3(0.8)$ & No \\
\hline 5 to 8 days before $\&$ after menstruation are non-fertile period & $25(6.4)$ & No \\
\hline 10 days before $\&$ after menstruation are non-fertile period & $3(0.8)$ & Yes \\
\hline First 5 to 8 days of a menstrual cycle are non-fertile period & $14(3.6)$ & No \\
\hline First 10 to 17 days of a menstrual cycle are non-fertile period & $22(5.6)$ & Yes \\
\hline $6^{\text {th }}-14^{\text {th }}$ days of a menstrual cycle are non-fertile period & $1(0.3)$ & Yes \\
\hline $15^{\text {th }}-20^{\text {th }}$ days of a menstrual cycle are non-fertile period & $1(0.3)$ & Yes \\
\hline 2 days before $\&$ after menstruation are fertile period & $3(0.8)$ & Yes \\
\hline 5 - 7 days before $\&$ after menstruation are fertile period & $30(7.7)$ & Yes \\
\hline 10 days before $\&$ after menstruation are fertile period & $4(1.0)$ & Yes \\
\hline First 8 days of a menstrual cycle are fertile period & $58(14.9)$ & Yes \\
\hline First 10 - 15 days of a menstrual cycle are fertile period & $123(31.5)$ & Yes \\
\hline First 17 - 18 days of a menstrual cycle are fertile period & $3(0.8)$ & Yes \\
\hline First 19 - 21 days of a menstrual cycle are fertile period & $11(2.8)$ & No \\
\hline $5^{\text {th }}-14^{\text {th }}$ days of a menstrual cycle are fertile period & $2(0.5)$ & Yes \\
\hline $7^{\text {th }}-20^{\text {th }}$ days of a menstrual cycle are fertile period & $2(0.5)$ & No \\
\hline $8^{\text {th }}-18^{\text {th }}$ days of a menstrual cycle are fertile period & $1(0.3)$ & No \\
\hline $8^{\text {th }}-23^{\text {rd }}$ days of a menstrual cycle are fertile period & $2(0.5)$ & No \\
\hline $9^{\text {th }}-16^{\text {th }}$ days of a menstrual cycle are fertile period & $1(0.3)$ & Yes \\
\hline $9^{\text {th }}-19^{\text {th }}$ days of a menstrual cycle are fertile period & $2(0.5)$ & No \\
\hline $10^{\text {th }}-18^{\text {th }}$ days of a menstrual cycle are fertile period & $11(2.8)$ & Yes \\
\hline $10^{\text {th }}-25^{\text {th }}$ days of a menstrual cycle are fertile period & $12(3.1)$ & Yes \\
\hline $12^{\text {th }}-26^{\text {th }}$ days of a menstrual cycle fertile period & $33(8.5)$ & Yes \\
\hline Don’t know & $23(5.9)$ & Yes \\
\hline
\end{tabular}


struation (3.6\%) as non-fertile period of menstrual cycle. Approximately, 15 percent women stated first 8 days of menstruation cycle as fertile window because they believed that mouth of the uterus is open and increased the risk of conception [10]. Also this logic may be true for women (31.5\%) who think that first 10 to 15 days of a menstrual cycle are fertile period. Sub-Saharan African women had low level of awareness of natural family planning methods and hence, wrong use of methods [9]. Wrong practice of method was also found in the present study. Among those who had heard of periodic abstinence, 7.7 percent (i.e. 30/390) of users were having correct knowledge of the fertile window, however 15.3 percent (60/390) women would not be at risk of unwanted pregnancy if they practice this method.

\section{CONCLUSION}

The decision to choose the periodic abstinence method as family planning method by couples may be influenced by many factors, but probably the most important factors are no side effects, no cost involvement, no threat to future fertility, no need to visit health facility, or dissatisfied with their past contraceptive modern methods [11]. It was found that women with higher education, belongs to nuclear family and history of using modern contraceptive method had correct knowledge and used periodic abstinence. The safe period method may be an effective strategy for reaching women who are not using any family planning method or are given limited choices for birth spacing or worried about side effects or experienced side effects of modern spacing method. It conveyed the need of intervention to provide the accurate knowledge to women so that those who select this method can practice it correctly. The counseling of safe period method may be incorporated relatively easily in national family program. Though this method cannot prevent the risk of sexually transmitted diseases but may help in reducing not only unwanted pregnancies but also repeated abortion to get rid of unintended pregnancies that may contribute enormously towards mothers and child health.

\section{ACKNOWLEDGEMENTS}

This study is part of the project entitled "Some epidemiological studies on unwanted pregnancies”, funded by Indian Council of Medi- cal Research (ICMR), New Delhi, India. Financial support from ICMR is gratefully acknowledged.

\section{REFERENCES}

[1] Curtis, S.L. and Neitzel, K. (1996) Contraceptive knowledge, use and sources, demographic and health surveys comparative studies. Macro International, Calverton.

[2] International Institute for Population Sciences (IIPS) and Macro International (2007) National family health survey (NFHS-3), 2005-06. IIPS, Mumbai.

[3] Pyper, C.M. (1997) Fertility awareness and natural family planning. European Journal of Contraception and Reproductive Health Care, 2, 131-146. doi:10.3109/13625189709167468

[4] Burkhart, M.C., de Mazariegos, L., Salazar, S. and Lamprecht, V.M. (2000) Effectiveness of a standard-rule method of calendar rhythm among Mayan couples in Guatemala. International Family Planning Perspectives, 26, 131-136. doi:10.2307/2648302

[5] Wilcox, A.J., David, D. and Donna, D.B. (2000) The timing of the "fertile window" in the menstrual cycle: Day specific estimates from a prospective study. British Medical Journal, 321, 1259-1262. doi:10.1136/bmj.321.7271.1259

[6] Arevalo, M., Sinai, I. and Jennings, V. (1999) A fixed formula to define the fertile window of the menstrual cycle as the basis of a simple method of natural family planning. Contraception, 60, 357-360. doi:10.1016/S0010-7824(99)00106-7

[7] Beckmann, C.R.B., Ling, F.W., Hebert, W.N.P., Laube, D.W., Smith, R.P. and Barzansky, B.M. (1998) Obstetrics and gynecology. Williams and Wilkins, Baltimore.

[8] Centre for Development and Population Activities (CEDPA) (2005) Expanding contraceptive choice: Integrating the standard days method (SDM) through public private partnership in India. Family planning and reproductive health. CEDPA, New Delhi.

[9] Audu, B., Yahya, S. and Bassi, A. (2006) Knowledge, attitude and practice of natural family planning methods in a population with poor utilisation of modern contraceptives. Journal of Obstetrics \& Gynaecology, 26, 555-560. doi:10.1080/01443610600811482

[10] Che, Y., John, G.C. and Mohamed, M.A. (2004) Periodic abstinence in developing countries: An assessment of failure rate and consequences. Contraception, 69, 15-21. doi:10.1016/j.contraception.2003.08.006

[11] Gribble, J.N. (2003) The standard days method of family planning: A response to Cairo. International Family Planning Perspectives, 29, 188-191. doi:10.2307/3181048 